\title{
Leguminosas herbáceas perenes para utilização como coberturas permanentes de solo na Caatinga Mineira ${ }^{1}$
}

\author{
Perennial herbaceous legumes used as permanent cover cropping in the Caatinga \\ Mineira
}

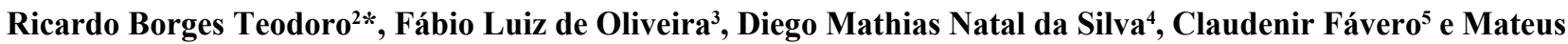 \\ Augusto Lima Quaresma ${ }^{6}$
}

\begin{abstract}
Resumo - O presente trabalho objetivou avaliar o comportamento e as potencialidades de leguminosas herbáceas perenes para o uso como cobertura permanente em solos da região da Caatinga Mineira, Médio Vale do Jequitinhonha, MG, visando a introdução dessas plantas de cobertura em áreas agrícolas. O experimento foi conduzido de dezembro de 2008 a julho de 2009. O delineamento experimental foi em blocos ao acaso, com seis tratamentos e quatro repetições. Os tratamentos foram constituídos pelas leguminosas: cudzu tropical (Pueraria phaseoloides), calopogônio (Calopogonium mucunoides), amendoim forrageiro (Arachis pintoi), soja perene (Glycine wightii), estilosantes (Stylosanthes capitata, Stylosanthes macrocephala) e pela testemunha (sem a presença de leguminosa). Foram avaliados os seguintes parâmetros: emergência das plântulas; taxa de cobertura do solo; promoção da retenção de umidade e temperatura do solo; capacidade de inibição da vegetação espontânea; potencial de deposição de folhas e de aporte de macronutrientes pela senescência de folhas; produção total de fitomassa seca e acúmulo de macronutrientes na parte aérea. A cobertura plena do solo foi alcançada pelo calopogônio, amendoim forrageiro e cudzu tropical. O calopogônio conferiu maior capacidade de retenção da umidade e inibição das plantas espontâneas. Em todos os tratamentos com leguminosas a temperatura do solo foi inferior à testemunha, a partir dos 120 dias de ciclo. Na região da Caatinga Mineira, as leguminosas perenes calopogônio e cudzu tropical, podem contribuir significativamente para o incremento de nitrogênio, aporte de outros macronutrientes (K, P, Ca e Mg) e incremento da matéria orgânica do solo.
\end{abstract}

Palavras-chave - Adubos verdes. Aporte de nutrientes. Sustentabilidade. Manejo do solo. Plantas de cobertura.

\begin{abstract}
The study objective was to evaluate the performance and potential of perennial herbaceous legumes for use as permanent soil cover in the Caatinga Mineira region MG, Brazil, for the introduction of these cover crops in agricultural areas. The experimental design was in a randomized blocks with six treatments and four replications. The treatments consisted on the leguminous: Pueraria phaseoloides, Calopogonium mucunoides, Arachis pintoi, Glycine wightii e Stylosanthes capitata, Stylosanthes macrocephala and the control (without the presence of leguminous). Were evaluated: seedling emergence and rate of soil cover, promotion of moisture retention and soil temperature, ability to inhibit the spontaneous vegetation, deposition potential of leaves and intake of macronutrients by senescence of leaves, dry matter production and accumulation of nutrients in the shoot. The full coverage of the soil was reached for Calopogonium mucunoides, Arachis pintoi and Pueraria phaseoloides. The Calopogonium mucunoides created greater capacity to retain moisture and inhibiting weeds. In all the treatments with leguminous, the soil temperature was lower than in control, from the 120 day cicle. In the region of Caatinga Mineira, the perennial leguminous Calopogonium mucunoides and Pueraria phaseoloides, could contribute significantly to the increase of the nitrogen and other macronutrients $(\mathrm{K}, \mathrm{P}, \mathrm{Ca}$ and $\mathrm{Mg})$ and the increase of organic matter under the soil.
\end{abstract}

Key words - Green manure. Nutrient input. Sustainability. Soil management. Cover crops.

\footnotetext{
*Autor para correspondência

${ }^{1}$ Recebido para publicação em 17/06/2010; aprovado em 14/03/2011

Parte da dissertação de Mestrado do primeiro autor, apresentada ao Programa de Pós-Graduação em Produção Vegetal, CCA/UFVJM; projeto financiado FAPEMIG, CNPq, MDA/SAF e MDS/SESAN

${ }^{2}$ Programa de Pós-Graduação em Produção Vegetal, CCA/UFVJM, Diamantina-MG, Brasil, ricardo.agronomia@hotmail.com

${ }^{3}$ Departamento de Agronomia, CCA/UFVJM, Diamantina-MG, Brasil, fabiocapi@yahoo.com.br

${ }_{4}^{4}$ Programa de Pós-Graduação em Produção Vegetal, CCA/UFVJM, Diamantina-MG, Brasil, diegoufvjm@yahoo.com.br

${ }^{5}$ Departamento de Agronomia, CCA/UFVJM, Diamantina-MG, Brasil, prufvjm@yahoo.com.br

${ }^{6}$ Graduando do Curso de Agronomia da Universidade Federal dos Vales do Jequitinhonha e Mucuri, Diamantina-MG, Brasil, mateusveio@yahoo.com.br
} 


\section{Introdução}

A degradação física e química do solo na região semi-árida está relacionada diretamente com o manejo inadequado do solo através das atividades agropecuárias, juntamente com as secas prolongadas e as chuvas, pois apesar de esporádicos os eventos chuvosos apresentamse em algumas épocas e locais com grande intensidade, o que associado à baixa eficiência dos sistemas agrícolas em proteger os solos, resulta em eventos degradantes de grande magnitude (ALBUQUERQUE et al., 2002).

Por outro lado, a degradação biológica está relacionada com a matéria orgânica do solo, cujo conteúdo é naturalmente baixo, em consequência das características da vegetação, clima e principalmente pelas ações antrópicas. $\mathrm{O}$ fornecimento limitado de matéria orgânica para o sistema pela baixa produção de fitomassa vegetal contribui, juntamente com o acentuado déficit de umidade, para diminuir tanto a atividade quanto à diversidade da fauna edáfica (CARVALHO, 1988). Todo esse processo é ainda acentuado quando há retirada da matéria orgânica nas camadas mais superiores do solo pela sua degradação, o que influencia a perda de nutrientes e microrganismos benéficos da superfície do solo quando este não está protegido (MELO FILHO; SOUZA, 2006).

Entretanto, a sustentabilidade destas áreas da Caatinga pode ser alcançada por meio do manejo adequado do solo no semi-árido, em que se ressalta o uso das plantas de cobertura (FARIA et al., 2004). A adoção da prática da adubação verde, realizada com espécies da Família Fabaceae, pode significar uma estratégia importante na busca da sustentabilidade dos agroecossistemas nesse bioma, visto os benefícios proporcionados ao solo, como melhorias das características físicas tais como agregação e incremento do carbono orgânico (PERIN et al., 2002), aporte de fitomassa e nutrientes para as áreas cultivadas (OLIVEIRA; GOSCH, 2007), fornecimento de N pela fixação biológica (GAMA-RODRIGUES et al., 2007), manutenção da umidade do solo, diminuição das temperaturas máximas e da amplitude térmica (TORRES et al., 2006), proteção permanente contra os principais agentes causadores da degradação dos solos (LEITE et al., 2010) e controle de plantas espontâneas (SILVA et al., 2009). Sobretudo, com utilização de espécies herbáceas perenes, que apresentam grande potencial como cobertura permanente de solo, por apresentarem algumas características, como recobrir o terreno em alguns meses ou durante todo o ano (PERIN et al., 2009).

A identificação das espécies leguminosas adaptadas às condições edafoclimáticas da região onde serão introduzidas é essencial para garantir o êxito do uso destas plantas como cobertura permanente, visto que o sucesso da prática depende de conhecimentos básicos como o comportamento, adaptação, exigência e período de permanência da espécie no ambiente no qual foi introduzida. Nos últimos anos intensificaram-se os estudos (ESPINDOLA et al., 2005; GUERRA et al., 2007; PERIN et al., 2009) com relação ao comportamento das leguminosas herbáceas perenes, no entanto, informações sobre o comportamento destas espécies nas condições da Caatinga são escassas, principalmente para a região do Médio Vale do Jequitinhonha em Minas Gerais, onde são inexistentes.

Assim este trabalho foi realizado com o objetivo de avaliar o comportamento e as potencialidades de espécies leguminosas herbáceas perenes para o uso como cobertura permanente em áreas agrícolas na região da Caatinga Mineira, Médio Vale do Jequitinhonha.

\section{Material e métodos}

O trabalho foi realizado na área experimental da Escola Família Agrícola de Jacaré - EFAJ, na comunidade de Jacaré, em Itinga-MG (16 $28^{\circ}$ '04" latitude Sul e 41 59 '50" longitude Oeste), na região de ocorrência do bioma Caatinga, no Médio Vale do Jequitinhonha. O local apresenta $672 \mathrm{~m}$ de altitude, com precipitação média acumulada no período de $659 \mathrm{~mm}$, temperatura mínima e máxima de 20,5 e $31,5^{\circ} \mathrm{C}$, respectivamente (INMET, 2009).

A área na qual se realizou o experimento encontravase em pousio, coberta pela vegetação espontânea, sendo o solo classificado como Argissolo Amarelo. Foram retiradas da área amostras de solo $(0-20 \mathrm{~cm})$, que apresentou as seguintes características químicas e granulométricas: $\mathrm{pH}$ em água 5,9; $29,3 \mathrm{mg} \mathrm{dm}^{-3}$ de PMehlich $1 ; 426 \mathrm{mg} \mathrm{dm}^{-3} \mathrm{de} \mathrm{K} ; 2,8 \mathrm{cmol}_{\mathrm{c}} \mathrm{dm}^{-3} \mathrm{de}$ $\mathrm{Ca} ; 1,8 \mathrm{cmol}_{\mathrm{c}} \mathrm{dm}^{-3} \mathrm{de} \mathrm{Mg} ; 0,2 \mathrm{cmol}_{\mathrm{c}} \mathrm{dm}^{-3} \mathrm{de} \mathrm{Al}$; saturação por bases igual a $63 \%$; areia $64 \%$, silte $10 \%$ e $26 \%$ argila.

O delineamento experimental foi em blocos ao acaso, com seis tratamentos e quatro repetições, tendo sido os tratamentos constituídos pelas leguminosas: cudzu tropical (Pueraria phaseoloides), calopogônio (Calopogonium mucunoides), amendoim forrageiro (Arachis pintoi), soja perene (Glycine wightii), estilosante campo grande (Stylosanthes capitata e Stylosanthes macrocephala) e pela testemunha (sem a presença de leguminosa).

Antes da semeadura foi realizada capina manual em toda a área do experimento, e as leguminosas foram semeadas em 04 de dezembro de 2008 (período chuvoso), na profundidade de $2 \mathrm{~cm}$, com espaçamento entre sulcos de $40 \mathrm{~cm}$ e densidade média de 20 sementes por metro de sulco. As sementes não sofreram nenhum tipo de tratamento para quebra de dormência. A área de cada parcela foi de $4 \mathrm{~m}^{2}(2 \times 2 \mathrm{~m})$, tendo sido considerada área útil os $2 \mathrm{~m}^{2}$ centrais. 
As características avaliadas nas leguminosas foram: emergência das plântulas; taxa de cobertura do solo; promoção da retenção de umidade e conservação da temperatura do solo; capacidade de inibição da vegetação espontânea; potencial de deposição de folhas e de aporte de macronutrientes pela senescência de folhas; produção total de fitomassa seca e acúmulo de macronutrientes na parte aérea.

A taxa de cobertura do solo foi determinada aos $30 ; 60 ; 90 ; 120 ; 150$ e 180 dias após a semeadura (DAS) das leguminosas, pelo método do número de interseções descrito por Fávero et al. (2001).

A temperatura do solo foi determinada nas profundidades de $5 ; 10$ e $15 \mathrm{~cm}$, aos $30 ; 60 ; 90 ; 120$ e 150 DAS, sempre às 14 horas. As leituras foram instantâneas, com auxílio de termômetro digital, modelo SoloTerm 1200, que utiliza sonda metálica.

A umidade volumétrica do solo foi determinada indiretamente por meio da densidade aparente do solo, pelo método padrão de estufa (BERNARDO et al., 2006), no período compreendido entre a semeadura e 180 DAS. As coletas foram realizadas mensalmente, nas profundidades de 0 a $5 \mathrm{~cm}$.

A capacidade de inibição da vegetação espontânea pelas leguminosas foi obtida por meio de avaliações da fitomassa seca total das plantas espontâneas realizadas no $1 \mathrm{~m}^{2}$ central das parcelas, aos 30; 60 e 120 DAS. A fitomassa seca foi determinada após secagem em estufa com ventilação de ar forçada à temperatura de $65^{\circ} \mathrm{C}$, por 72 horas.

O potencial de deposição de folhas e aporte de macronutrientes pelas leguminosas foi obtido pela quantificação da fitomassa senescente depositada sobre o solo e pelo acúmulo de macronutrientes nesta fitomassa, na área útil de $1 \mathrm{~m}^{2}$ central. As coletas foram realizadas aos 90; 120; 150 e 180 DAS.

Para determinação do acúmulo total de fitomassa seca na parte aérea foi realizado o corte das plantas aos 180 DAS e a pesagem da fitomassa verde total produzida. $\mathrm{O}$ acúmulo da fitomassa seca foi determinado indiretamente, por meio da umidade do material verde, aferida em amostras de $100 \mathrm{~g}$, que foram secas em estufa de ventilação de ar forçada a $65^{\circ} \mathrm{C}$, por 72 horas, até atingir massa constante. Nessa fitomassa também foi estimado o acúmulo de macronutrientes.

Nas análises químicas dos materiais, o teor de $\mathrm{N}$ foi determinado após digestão sulfúrica e destilação pelo Método Kjeldahl (BREMNER; MULVANEY, 1982); os teores de $\mathrm{P}, \mathrm{K}, \mathrm{Ca}$ e $\mathrm{Mg}$ foram determinados após digestão nítrico-perclórica (BATAGLIA et al., 1983) tendo sido o $\mathrm{P}$ determinado em espectrofotômetro a partir de formação da cor azul do complexo fosfato-molibdato em meio sulfúrico, na presença de ácido ascórbico como redutor. O $\mathrm{K}$ foi determinado por fotômetro de chama e o Ca e $\mathrm{Mg}$ em espectrofotômetro de absorção atômica (Embrapa, 1997).

As análises estatísticas foram realizadas com auxílio do programa estatístico SISVAR (FERREIRA, 2008). Os dados foram submetidos à análise de variância pelo Teste $\mathrm{F}$ e as médias comparadas pelo Teste Tukey a 5\% de significância.

\section{Resultados e discussão}

Não houve diferenças entre as leguminosas quanto ao tempo de emergência das plântulas. A maioria das espécies apresentou valores iguais ou superiores a $80 \%$ de emergência aos 7 dias após semeadura.

O calopogônio e o amendoim forrageiro apresentaram as maiores porcentagens de cobertura de solo, em torno de 87 e $74 \%$ respectivamente, aos 90 DAS (FIG 1). O rápido estabelecimento inicial do amendoim forrageiro pode estar ligado à alta densidade de plantas e fertilidade do solo, o que favoreceu seu estabelecimento na área. $\mathrm{O}$ cudzu tropical apresentou crescimento inicial mais lento, quando comparado ao calopogônio e ao amendoim forrageiro, contudo, a partir dos 120 dias as três espécies cobriram o solo totalmente. Comportamento semelhante também foi identificado por Perin et al. (2000) e Guerra et al. (2007), na região de Mata Atlântica, para as leguminosas calopogônio, cudzu tropical e amendoim forrageiro ao observarem que o período médio para total cobertura do solo foi de 106; 106 e 114 dias, respectivamente. No presente trabalho, essas três espécies foram as que apresentaram as maiores taxas de cobertura de solo até os 180 DAS, com destaque para o calopogônio. A soja perene apresentou o máximo de $88 \%$ de cobertura do solo, aos 120 dias, momento em que o estilosantes apresentou o máximo de $63 \%$ de cobertura de solo (FIG. 1).

Todas as espécies iniciaram um processo de redução na taxa de cobertura do solo a partir dos 120 dias, o que ficou mais evidente para as espécies estilosantes, soja perene e amendoim forrageiro (FIG. 1). Isto ocorreu em razão das altas temperaturas e da escassez de água (chuvas), já que se iniciava o período da seca, característico da região de Caatinga. À medida em que o período da seca na região se aproxima as plantas respondem com expressiva senescência de folhas, o que reduz a proteção do solo, embora, quando este material não é retirado da área, também contribui para cobertura do solo (GUERRA et al., 2007).

O estilosantes apresentou, em todas as parcelas, plantas em pleno florescimento aos 120 dias. A soja perene e o calopogônio apresentaram plena floração aos 150 dias. A floração mais tardia foi a do cudzu tropical 


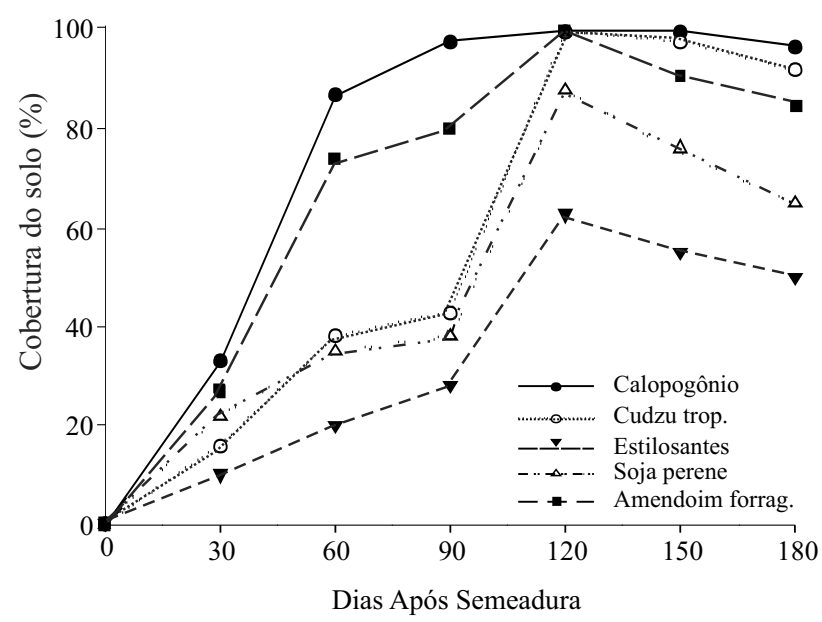

Figura 1 - Cobertura do solo por leguminosas, na região de Caatinga, no Médio Vale do Jequitinhonha

que apresentou em torno de $20 \%$ das plantas com flores, a partir dos 150 dias, o que perdurou até os 180 dias. Esse comportamento das espécies, exceto o cudzu tropical, fortalece o potencial destas para uso como cobertura viva permanente no ambiente estudado, pois a produção de sementes anterior ao período da seca pode garantir o aproveitamento das sementes para nova semeadura das áreas, o que representa uma alternativa de manutenção das espécies. Desta forma, as espécies avaliadas, poderiam se restabelecer com maior facilidade, quando retornasse o período chuvoso.

Quanto à capacidade de inibição do crescimento de plantas espontâneas pelas leguminosas, observou-se que nos primeiros $30 \mathrm{DAS}$, não houve diferença significativa entre as espécies, e que nenhuma delas apresentou efetiva capacidade de inibição. Aos 60 dias percebeu-se que o calopogônio e o amendoim forrageiro foram as espécies que mais inibiram o crescimento de plantas espontâneas, tendo reduzido a fitomassa acumulada das mesmas, enquanto as demais espécies não diferiam entre si. Aos 90 dias, o calopogônio se destacou por inibir totalmente a presença das espontâneas (FIG. 2).

Cabe ressaltar, que o crescimento mais lento das leguminosas perenes nos primeiros 90 dias não proporcionou boa cobertura do solo, o que favoreceu a presença das espontâneas. Porém, passado esse estádio inicial do desenvolvimento, a capacidade de inibição ocorreu por meio da capacidade de competição das leguminosas pelos fatores de crescimento e de possíveis efeitos alelopáticos, com a produção de determinados compostos inibidores, que reduzem a presença das espontâneas, o que reflete na menor necessidade de mão-deobra para seu controle. Fernandes et al. (1999), citam que a reduzida velocidade de crescimento inicial das leguminosas perenes reflete em menor inibição das plantas espontâneas inicialmente, entretanto após esta fase, competem pelos recursos disponíveis, apresentando elevado potencial de inibição. Especificamente para o calopogônio, variações na intensidade dos efeitos alelopáticos dos compostos inibidores da germinação, depende de fatores relacionados à espécie doadora e receptora, entretanto alguns resultados de pesquisa indicam que existe possibilidades de manejo dessa leguminosa, visando maximizar a sua atividade potencialmente alelopática (SOUZA FILHO et al., 2003).

Quanto à variação da temperatura do solo, sob a cobertura das diferentes leguminosas, nota-se diferenças entre algumas das leguminosas e a testemunha, em todas as épocas e profundidades avaliadas. Observou-se que a cobertura do solo com o calopogônio, em todos os períodos avaliados, promoveu a redução da temperatura do solo em comparação com a testemunha (TAB. 1).

As temperaturas observadas na profundidade de 5 $\mathrm{cm}$ foram maiores que a 10 e $15 \mathrm{~cm}$, o que está relacionado a maior incidência de raios solares e poder acumulativo do solo em relação à temperatura. $\mathrm{O}$ calopogônio apresentou os menores valores de temperatura do solo nas profundidades avaliadas, diferenciando-se das demais leguminosas, no período em que apresentava aproximadamente 90\% de cobertura do solo (FIG. 1). Isto contribuiu diretamente para diminuir a temperatura do solo, o que demonstra que a espécie apresenta a capacidade de promover reduções de temperatura do solo, em menor tempo (DAS) em relação às demais. As espécies variaram quanto à redução da temperatura do solo nos primeiros 90 dias, contudo a partir dos 120 dias todas proporcionam redução efetiva da temperatura do solo no horário das 14 horas.

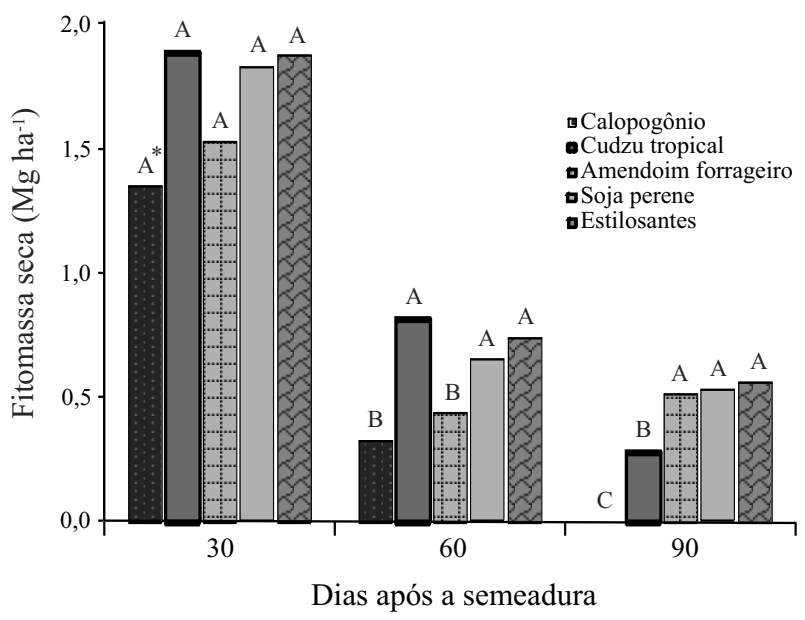

Figura 2 - Acúmulo de fitomassa seca total das plantas espontâneas aos 30, 60 e 90 dias após semeadura, nas áreas cultivadas com diferentes leguminosas. *Valores seguidos de letras iguais, na mesma data, não diferem entre si pelo Teste Tukey $(\mathrm{p}<0,05)$ 
Tabela 1 - Temperatura do solo, com diferentes coberturas, no horário das 14:00 horas, medidas nas profundiades de 5,10 e $15 \mathrm{~cm}$, aos $30,60,90,120$ e 150 dias após semeadura ${ }^{1}$

\begin{tabular}{|c|c|c|c|c|c|}
\hline \multirow{3}{*}{ Espécies } & 30 DAP & 60 DAP & 90 DAP & 120 DAP & 150 DAP \\
\hline & \multicolumn{5}{|c|}{ Temperatura ${ }^{\circ} \mathrm{C}$} \\
\hline & \multicolumn{5}{|c|}{$5 \mathrm{~cm}$} \\
\hline Calopogônio & $32,3 \mathrm{~d}^{1}$ & $29,9 \mathrm{~d}$ & $36,9 \mathrm{~d}$ & $23,9 \mathrm{e}$ & $31,1 \mathrm{~b}$ \\
\hline Cudzu tropical & $35,3 \mathrm{bc}$ & $38,0 \mathrm{~b}$ & $42,6 \mathrm{~b}$ & $25,4 \mathrm{~cd}$ & $31,7 \mathrm{~b}$ \\
\hline Estilosantes & $36,6 \mathrm{ab}$ & $39,7 \mathrm{ab}$ & $43,9 \mathrm{ab}$ & $28,3 \mathrm{~b}$ & $33,7 \mathrm{~b}$ \\
\hline Amendoim & $34,1 \mathrm{~cd}$ & $32,5 \mathrm{c}$ & $39,5 \mathrm{c}$ & $24,5 \mathrm{de}$ & $30,2 \mathrm{~b}$ \\
\hline Soja perene & $36,6 a b c$ & $39,0 \mathrm{ab}$ & $43,6 \mathrm{ab}$ & $26,3 \mathrm{c}$ & $31,8 \mathrm{~b}$ \\
\hline \multirow[t]{2}{*}{ Testemunha } & $38,0 \mathrm{a}$ & $40,8 \mathrm{a}$ & $45,2 \mathrm{a}$ & $34,2 \mathrm{a}$ & $42,4 \mathrm{a}$ \\
\hline & \multicolumn{5}{|c|}{$10 \mathrm{~cm}$} \\
\hline Calopogônio & $29,8 \mathrm{~d}$ & $29,1 \mathrm{c}$ & $34,1 \mathrm{~d}$ & $23,4 d$ & $28,7 \mathrm{c}$ \\
\hline Cudzu tropical & $31,9 \mathrm{bcd}$ & $37,2 \mathrm{a}$ & $40,2 \mathrm{bc}$ & $24,7 \mathrm{c}$ & $30,1 \mathrm{bc}$ \\
\hline Estilosantes & $33,6 \mathrm{ab}$ & $38,3 \mathrm{a}$ & $41,1 \mathrm{ab}$ & $27,2 \mathrm{~b}$ & $32,5 \mathrm{~b}$ \\
\hline Amendoim & $31,1 \mathrm{~cd}$ & $31,5 \mathrm{~b}$ & $38,1 \mathrm{c}$ & $23,5 \mathrm{~d}$ & $29,2 \mathrm{c}$ \\
\hline Soja perene & $33,7 \mathrm{ab}$ & $37,5 \mathrm{a}$ & $41,8 \mathrm{ab}$ & $25,7 \mathrm{c}$ & $30,8 \mathrm{bc}$ \\
\hline \multirow[t]{2}{*}{ Testemunha } & $35,4 \mathrm{a}$ & $39,4 \mathrm{a}$ & $42,9 \mathrm{a}$ & $30,9 \mathrm{a}$ & $39,6 \mathrm{a}$ \\
\hline & \multicolumn{5}{|c|}{$15 \mathrm{~cm}$} \\
\hline Calopogônio & $28,2 \mathrm{c}$ & $28,5 \mathrm{~b}$ & $34,8 \mathrm{c}$ & $23,0 \mathrm{~d}$ & $27,1 \mathrm{c}$ \\
\hline Cudzu tropical & $29,5 \mathrm{bc}$ & $35,6 \mathrm{a}$ & $38,0 \mathrm{ab}$ & $24,1 \mathrm{c}$ & $28,4 \mathrm{bc}$ \\
\hline Estilosantes & $30,8 \mathrm{ab}$ & $36,2 \mathrm{a}$ & $38,8 \mathrm{a}$ & $26,4 \mathrm{~b}$ & $30,9 \mathrm{~b}$ \\
\hline Amendoim & $29,1 \mathrm{bc}$ & $30,4 \mathrm{~b}$ & $36,2 \mathrm{bc}$ & $23,3 \mathrm{~d}$ & $27,8 \mathrm{c}$ \\
\hline Soja perene & $31,1 \mathrm{ab}$ & $35,8 \mathrm{a}$ & $39,6 \mathrm{a}$ & $25,1 \mathrm{c}$ & $29,2 \mathrm{bc}$ \\
\hline Testemunha & $32,2 \mathrm{a}$ & $37,2 \mathrm{a}$ & $40,1 \mathrm{a}$ & $27,6 \mathrm{a}$ & $37,1 \mathrm{a}$ \\
\hline $\mathrm{CV} \%$ & 4,15 & 3,61 & 3,46 & 2,34 & 5,48 \\
\hline
\end{tabular}

${ }^{1}$ Valores seguidos de letras iguais, dentro da coluna, não diferem entre si pelo Teste Tukey $(\mathrm{p}<0,05)$

Verificou-se diferença significativa no volume de água acumulado no solo sob a cobertura das diferentes leguminosas (TAB. 2). Aos 150 e 180 dias apenas o calopogônio se destacou e as demais espécies não diferiram entre si (TAB. 2) o que demonstra a maior capacidade do calopogônio em conservar a umidade do solo, na situação da Caatinga Mineira. Este desempenho do calopogônio em relação às demais leguminosas pode estar relacionado à maior capacidade de cobertura (FIG. 1), deposição de folhas senescentes e redução de temperatura (TAB. 1), o que aumenta a proteção contra a incidência direta dos raios solares, ameniza as temperaturas, por diminuir a amplitude térmica, e acarreta menor evapotranspiração e conservação da umidade do solo. Qualquer cobertura na superfície do solo constitui-se numa barreira física à transferência de energia e vapor d'água entre o solo e atmosfera, o que aumenta a capacidade de manutenção da umidade do solo (STRECK et al., 1994).
A baixa umidade do solo identificada nas diferentes coberturas de solo com leguminosas pode ser explicada, em parte, por ser o solo estudado de textura franco arenosa, que apresenta baixa capacidade de retenção de água. Porém, em se tratando de um bioma onde o déficit hídrico é um dos principais limitadores para o desenvolvimento das atividades agrícolas, o uso destas coberturas pode amenizar as perdas de água nos períodos críticos, principalmente as leguminosas com maior potencial para queda natural de folhas, como é o caso do calopogônio, cudzu tropical e soja perene. Os resíduos de coberturas vegetais promovem uma retenção da água na sua estrutura, liberando-a gradativamente ao solo e deixando-o mais úmido na camada superficial por se encontrar em contato direto com os mesmos (OLIVEIRA; SOUZA, 2003).

A deposição de folhas senescentes e aporte de macronutrientes para o solo, mostrou-se diferente 
Tabela 2 - Volume de água na camada de $0-5 \mathrm{~cm}$ do solo, em seis épocas, para as diferentes coberturas de solo

\begin{tabular}{lcccccc}
\hline \multirow{2}{*}{ Espécie } & \multicolumn{5}{c}{ Volume de água no solo $\left(\mathrm{cm}^{3} \mathrm{~cm}^{-3}\right)$} \\
\cline { 2 - 6 } & 30 & 60 & 90 & 120 & 150 & 180 \\
\cline { 2 - 6 } Calopogônio & $0,121 \mathrm{a}^{1}$ & $0,099 \mathrm{a}$ & $0,068 \mathrm{a}$ & $0,136 \mathrm{a}$ & $0,082 \mathrm{a}$ & $0,069 \mathrm{a}$ \\
Cudzu trop. & $0,079 \mathrm{c}$ & $0,087 \mathrm{ab}$ & $0,030 \mathrm{~b}$ & $0,092 \mathrm{bc}$ & $0,066 \mathrm{~b}$ & $0,043 \mathrm{~b}$ \\
Estilosantes & $0,078 \mathrm{c}$ & $0,074 \mathrm{~b}$ & $0,031 \mathrm{~b}$ & $0,074 \mathrm{c}$ & $0,052 \mathrm{~b}$ & $0,038 \mathrm{~b}$ \\
Amendoim & $0,101 \mathrm{~b}$ & $0,090 \mathrm{ab}$ & $0,064 \mathrm{a}$ & $0,106 \mathrm{~b}$ & $0,066 \mathrm{~b}$ & $0,051 \mathrm{~b}$ \\
Soja perene & $0,087 \mathrm{c}$ & $0,097 \mathrm{a}$ & $0,034 \mathrm{~b}$ & $0,105 \mathrm{~b}$ & $0,065 \mathrm{~b}$ & $0,043 \mathrm{~b}$ \\
\hline $\mathrm{CV}(\%)$ & 6,97 & 11,20 & 13,62 & 11,02 & 9,99 & 15,28 \\
\hline
\end{tabular}

${ }^{1}$ Valores seguidos de letras iguais, dentro da coluna, não diferem entre si pelo teste Tukey $(\mathrm{p}<0,05)$

entre as leguminosas, tendo variado de acordo com o desenvolvimento delas. Aos 90 dias apenas o calopogônio apresentava aporte de material senescente sobre o solo. Aos 120 dias, as demais espécies, exceto o estilosantes, iniciaram o aporte de matéria orgânica e nutrientes para o solo, através da fitomassa senescente. Somente aos 180 dias observou-se senescência de folhas pelo estilosantes (TAB. 3).

Observa-se que o calopogônio, além de ter iniciado a deposição de material mais precocemente, apresentou os maiores valores depositados mostrando sua maior capacidade de incorporação de matéria orgânica ao solo e de contribuição com o aporte de nutrientes. A partir dos 120 dias, o cudzu tropical e a soja perene, se destacam com o segundo melhor potencial (TAB. 3). Diante dos resultados para as condições desse experimento, o calopogônio, cudzu tropical e soja perene, demonstraram significativa capacidade para deposição de matéria orgânica sobre o solo, com destaque para o calopogônio, o que ressalta o potencial para utilização destas espécies como plantas companheiras, principalmente como cobertura permanente de solos em cultivos perenes, como pomares e os quintais agroflorestais, que são comuns na região.

As leguminosas apresentaram diferentes potenciais para o aporte de nutrientes, promovido pela deposição das folhas senescentes. O calopogônio, aportou as maiores quantidades de $\mathrm{N}$ e acumulou as maiores quantidades de P, K, Ca e Mg no período dos 90 aos 180 dias de ciclo, como reflexo da sua capacidade de deposição de folhas senescentes. Observa-se ainda, que o cudzu tropical e a soja perene proporcionaram acúmulo considerável de macronutrientes (TAB. 3). Percebe-se que o calopogônio, cudzu tropical e soja perene, podem contribuir significativamente para o incremento de nitrogênio e dos demais nutrientes, além de favorecer o aumento da matéria orgânica sobre o solo, por meio da fitomassa senescente, proporcionando assim benefícios aos atributos químicos, físicos e biológicos (PERIN et al., 2007).
O calopogônio destacou-se quanto ao acúmulo de fitomassa seca, apresentando valores superiores às demais leguminosas (TAB. 4), e valores superiores aos observados por Daher et al. (2002), Nascimento e Silva (2004) e Espindola et al. (2005), em estudos na região de Mata Atlântica, o que pode está relacionado à fertilidade do solo e à boa distribuição das chuvas no período de avaliação do experimento. A quantidade de fitomassa acumulada pelo calopogônio, foi 68,$6 ; 123,6 ; 271,25$ e 303,96\% superiores à do cudzu tropical, estilosantes, amendoim forrageiro e soja perene, respectivamente. O cudzu tropical e o estilosantes apresentaram acúmulo de fitomassa seca intermediário, com o amendoim forrageiro e a soja perene apresentando os menores desempenhos (TAB. 4).

Com relação ao acúmulo de macronutrientes, os maiores valores foram observados para o calopogônio, seguido pelo cudzu tropical (TAB. 4). O manejo da cobertura permanente com as leguminosas permite aumentar a quantidade de matéria orgânica depositada sobre o solo, aporte de macronutrientes, visto a capacidade de algumas dessas espécies em depositar sobre o solo, quantidades significativas de fitomassa senescente e da parte aérea, além da facilidade de rebrote das mesmas após o corte.

De todos os nutrientes acumulados na fitomassa das leguminosas, o $\mathrm{N}$ representa um real aporte ao sistema, principalmente pelo incremento do elemento ao solo pela fixação simbiótica. Campello et al. (2008) verificaram que do total de $\mathrm{N}$ acumulado no calopogônio, 71,9\% são oriundos da fixação biológica de nitrogênio (FBN), Espindola et al. (2006) em estudo com o cudzu tropical e amendoim forrageiro, identificaram que nestas espécies os valores de $\mathrm{N}$ oriundos da FBN foram de 86,2 e 66,9\% respectivamente; enquanto o estilosantes e a soja perene teriam em média, $70 \%$ do $\mathrm{N}$ total proveniente da FBN, segundo afirmativa de Giller (2001). Tomando como referência esses valores, pode-se estimar que os valores de $\mathrm{N}$ aportados via FBN pelas leguminosas no presente 
Tabela 3 - Deposição de fitomassa seca e acúmulo de macronutrientes pela deposição de material senescentes das leguminosas, durante o ciclo

\begin{tabular}{|c|c|c|c|c|c|c|}
\hline \multirow{2}{*}{ Espécie } & MS & $\mathrm{N}$ & $\mathrm{P}$ & $\mathrm{K}$ & $\mathrm{Ca}$ & $\mathrm{Mg}$ \\
\hline & $\mathrm{Mg} \mathrm{ha}^{-1}$ & $\mathrm{~kg} \mathrm{ha}^{-1}$ & $\mathrm{~kg} \mathrm{ha}^{-1}$ & $\mathrm{~kg} \mathrm{ha}^{-1}$ & $\mathrm{~kg} \mathrm{ha}^{-1}$ & $\mathrm{~kg} \mathrm{ha}^{-1}$ \\
\hline & \multicolumn{6}{|c|}{90 dias após plantio } \\
\hline Calopogônio & 0,63 & 9,76 & 0,79 & 7,77 & 7,13 & 3,97 \\
\hline Cudzu tropical & - & - & - & - & - & - \\
\hline Estilosantes & - & - & - & - & - & - \\
\hline Amendoim & - & - & - & - & - & - \\
\hline Soja perene & - & - & - & - & - & - \\
\hline \multirow[t]{2}{*}{$\mathrm{CV} \%$} & - & - & - & - & - & - \\
\hline & \multicolumn{6}{|c|}{120 dias após plantio } \\
\hline Calopogônio & $1,66 \mathrm{a}^{1}$ & $29,8 \mathrm{a}$ & $1,90 \mathrm{a}$ & $17,7 \mathrm{a}$ & $20,9 \mathrm{a}$ & $13,4 \mathrm{a}$ \\
\hline Cudzu tropical & $0,32 \mathrm{~b}$ & $4,2 \mathrm{c}$ & $0,24 \mathrm{c}$ & $2,7 \mathrm{~b}$ & $3,1 \mathrm{c}$ & $2,4 \mathrm{c}$ \\
\hline Estilosantes & - & - & - & - & - & - \\
\hline Amendoim & $0,39 \mathrm{~b}$ & $8,1 \mathrm{~b}$ & $0,66 \mathrm{~b}$ & $5,2 \mathrm{~b}$ & $7,3 \mathrm{~b}$ & $4,5 \mathrm{~b}$ \\
\hline Soja perene & $0,30 \mathrm{~b}$ & $2,8 \mathrm{c}$ & $0,28 \mathrm{c}$ & $2,8 \mathrm{~b}$ & $2,8 \mathrm{c}$ & $2,5 \mathrm{c}$ \\
\hline \multirow[t]{2}{*}{$\mathrm{CV} \%$} & 9,45 & 14,80 & 19,64 & 21,12 & 17,09 & 12,60 \\
\hline & \multicolumn{6}{|c|}{150 dias após plantio } \\
\hline Calopogônio & $1,88 \mathrm{a}$ & $46,1 \mathrm{a}$ & $2,9 \mathrm{a}$ & $18,3 \mathrm{a}$ & $18,7 \mathrm{a}$ & $15,8 \mathrm{a}$ \\
\hline Cudzu tropical & $0,70 \mathrm{~b}$ & $14,1 \mathrm{~b}$ & $1,2 \mathrm{~b}$ & $6,2 \mathrm{~b}$ & $8,8 \mathrm{~b}$ & $5,5 \mathrm{~b}$ \\
\hline Estilosantes & - & - & - & - & - & - \\
\hline Amendoim & $0,24 \mathrm{c}$ & $4,8 \mathrm{c}$ & $0,3 \mathrm{c}$ & $2,1 \mathrm{~b}$ & $4,4 \mathrm{c}$ & $3,2 \mathrm{c}$ \\
\hline Soja perene & $0,80 \mathrm{~b}$ & $13,2 \mathrm{~b}$ & $0,9 \mathrm{~b}$ & $8,5 \mathrm{~b}$ & $9,1 \mathrm{~b}$ & $6,8 \mathrm{~b}$ \\
\hline \multirow[t]{2}{*}{$\mathrm{CV} \%$} & 7,45 & 10,50 & 12,57 & 35,03 & 8,50 & 8,85 \\
\hline & \multicolumn{6}{|c|}{180 dias após plantio } \\
\hline Calopogônio & $2,71 \mathrm{a}$ & $61,6 \mathrm{a}$ & $5,7 \mathrm{a}$ & $40,4 \mathrm{a}$ & $36,1 \mathrm{a}$ & $20,5 \mathrm{a}$ \\
\hline Cudzu tropical & $1,46 \mathrm{~b}$ & $29,7 \mathrm{~b}$ & $1,9 \mathrm{bc}$ & $18,1 \mathrm{c}$ & $18,5 \mathrm{~b}$ & $14,4 \mathrm{~b}$ \\
\hline Estilosantes & $0,92 \mathrm{c}$ & $12,6 \mathrm{c}$ & $1,6 \mathrm{bc}$ & $7,2 \mathrm{~d}$ & $9,7 \mathrm{c}$ & $4,7 \mathrm{~d}$ \\
\hline Amendoim & $0,59 \mathrm{~d}$ & $12,7 \mathrm{c}$ & $1,0 \mathrm{c}$ & $8,5 \mathrm{~d}$ & $12,1 \mathrm{c}$ & $7,4 \mathrm{c}$ \\
\hline Soja perene & $1,32 \mathrm{~b}$ & $25,7 \mathrm{~b}$ & $2,4 \mathrm{~b}$ & $26,3 \mathrm{~b}$ & $18,1 \mathrm{~b}$ & $12,2 \mathrm{~b}$ \\
\hline $\mathrm{CV} \%$ & 6,74 & 9,75 & 18,35 & 12,82 & 9,82 & 10,00 \\
\hline
\end{tabular}

${ }^{1}$ Valores seguidos de letras iguais, dentro da coluna, não diferem entre si pelo teste Tukey $(\mathrm{p}<0,05)$

Tabela 4 - Acúmulo de Fitomassa, Nitrogênio, Fósforo, Potássio, Cálcio e Magnésio na parte aérea das leguminosas, aos 180 dias de ciclo

\begin{tabular}{lcccccc}
\hline \multirow{2}{*}{ Espécies } & Massa Seca & $\mathrm{N}$ & $\mathrm{P}$ & $\mathrm{K}$ & $\mathrm{Ca}$ & $\mathrm{Mg}$ \\
\cline { 2 - 7 } & $\mathrm{Mg} \mathrm{ha}^{-1}$ & & & $\mathrm{~kg} \mathrm{ha}^{-1}$ & & \\
\hline Calopogônio & $9,17 \mathrm{a}^{1}$ & $234,25 \mathrm{a}$ & $19,33 \mathrm{a}$ & $137,43 \mathrm{a}$ & $119,56 \mathrm{a}$ & $68,58 \mathrm{a}$ \\
Cudzu trop. & $5,45 \mathrm{~b}$ & $146,91 \mathrm{~b}$ & $10,60 \mathrm{~b}$ & $87,54 \mathrm{~b}$ & $53,43 \mathrm{~b}$ & $52,95 \mathrm{~b}$ \\
Estilosantes & $4,10 \mathrm{c}$ & $73,84 \mathrm{c}$ & $9,64 \mathrm{~b}$ & $59,95 \mathrm{c}$ & $46,68 \mathrm{bc}$ & $20,77 \mathrm{c}$ \\
Amendoim & $2,47 \mathrm{~d}$ & $61,62 \mathrm{c}$ & $4,36 \mathrm{c}$ & $47,15 \mathrm{~cd}$ & $30,54 \mathrm{~cd}$ & $23,69 \mathrm{c}$ \\
Soja perene & $2,27 \mathrm{~d}$ & $56,35 \mathrm{c}$ & $4,65 \mathrm{c}$ & $41,38 \mathrm{~d}$ & $29,59 \mathrm{~d}$ & $21,52 \mathrm{c}$ \\
\hline $\mathrm{CV}(\%)$ & 11,47 & 14,65 & 11,20 & 10,52 & 12,94 & 13,41 \\
\hline
\end{tabular}

${ }^{1}$ Valores seguidos de letras iguais, dentro da coluna, não diferem entre si pelo Teste Tukey $(p<0,05)$ 
trabalho, representam quantidades suficientes para suprir as necessidades de $\mathrm{N}$ de uma gama de culturas.

Tendo em vista que as espécies leguminosas perenes apresentam rebrota após o corte, estas podem promover elevada incorporação de matéria orgânica aos solos, ao longo dos anos, por meio da senescência das folhas ou da realização de cortes, o que torna este aspecto relevante no manejo destas como coberturas permanentes. Outro aspecto relevante ao uso dessas espécies na região da Caatinga Mineira, é que a fitomassa acumulada, além do uso na atividade agrícola, também pode representar uma interessante alternativa para a atividade pecuária, principalmente na alimentação de bovinos e caprinos.

\section{Conclusões}

1. O calopogônio, amendoim forrageiro e cudzu tropical, apresentam maior capacidade em porcentagem para cobertura do solo;

2. As leguminosas promovem redução da temperatura do solo após 120 dias do plantio;

3. O calopogônio confere maior capacidade de retenção da umidade e inibição das plantas espontâneas;

4. O calopogônio e cudzu tropical, contribuiram para o incremento do N, além do aumento da matéria orgânica sobre o solo, por meio do material senescente e da parte aérea acumulada pelas mesmas.

\section{Agradecimentos}

À Escola Família Agrícola de Jacaré pelo apoio oferecido na realização deste trabalho; à FAPEMIG; CNPq; MAD/SAF; MDS/SESAN pelo auxílio financeiro e UFVJM pelo suporte à pesquisa.

\section{Referências}

ALBUQUERQUE, A. W. et al. Manejo da cobertura do solo e de práticas conservacionistas nas perdas de solo e água em Sumé, PB. Revista Brasileira de Engenharia Agrícola e Ambiental, v. 06, n. 01, p. 136-141, 2002.

BATAGLIA, O. C. et al. Método de análise química de plantas. Boletim Técnico do Instituto Agronômico, Campinas, n. 78, p. 1- 48, 1983.

BERNARDO, S.; SOARES, A. A.; MANTOVANI, E. C. Manual de irrigação. 8. ed. Viçosa: UFV, 2006. 625 p.

BREMNER, J. M.; MULVANEY, C. S. Nitrogen total, In: PAGE, A. L.; MILLER, R. A.; KEENEY, D. R. (Ed.). Methods of soil Analysis. 2. ed. Madison: American Society of agronomy, 1982. p. 595-624. (Agronomy, 9).

CAMPELlO, E. F. C. et al. Avaliação de genótipos de dendê quanto à adaptação em áreas alteradas pela mineração de bauxita em Porto Trombetas, município de Oriximiná, PA. Seropédica: Embrapa Agrobiologia, 2008. 26 p. (Documentos, 255).

CARVAlHO, O. A economia política do Nordeste: secas irrigação e desenvolvimento. Rio de Janeiro: Campus, 1988. 505 p.

DAHER, R. F. et al. Introdução e avaliação de 19 leguminosas forrageiras em Campos dos Goytacazes, RJ. Revista Ceres, v. 49, n. 283, p. 223-230, 2002.

EMBRAPA. Centro Nacional de Pesquisa de Solos. Manual de métodos de análise de solo. Rio de Janeiro, 1997. 212 p.

ESPINDOLA, J. A. A. et al. Bananeiras consorciadas com leguminosas herbáceas perenes utilizadas como cobertura vivas. Pesquisa Agropecuária Brasileira, v. 41, n. 03, p. 415-420, 2006.

ESPINDOLA, J. A. A. et al. Evaluantion of perennial herbaceous legumes with different phosphorus sources and levels in Brasilian Utisol. Renewable Agriculture and Food Systems, v. 01, n. 20, p. 56-62, 2005.

FARIA, C. M. B. et al. Adubação verde com leguminosas em videira no submédio São Francisco. Revista Brasileira de Ciência do Solo, v. 28, n. 04, p. 641-648, 2004.

FÁVERO, C. et al. Modificações na população de plantas espontâneas na presença de adubos verdes. Pesquisa Agropecuária Brasileira, v. 36, n. 11, p. 1355-1362, 2001.

FERNANDES, M. F.; BARRETO, A. C.; FILHO, J. E. Fitomassa de adubos verdes e controle de plantas daninhas em diferentes densidades populacionais de leguminosas. Pesquisa Agropecuária Brasileira, v. 34, n. 9, p. 1595-1600, 1999.

FERREIRA, D. F. SISVAR: um programa para análises e ensino de estatística. Revista Symposium, v. 06, n. 02, p. 36-41, 2008.

GAMA-RODRIGUES, A. C.; GAMA-RODRIGUES, E. F.; BRITO, E. C. Decomposição e liberação de nutrientes de resíduos culturais de plantas de cobertura em argissolo vermelhoamarelo na região noroeste fluminense (RJ). Revista Brasileira de Ciência do Solo, v. 31, n. 06, p. 1421-1428, 2007.

GILLER, K. E. Nitrogen fixation in tropical cropping systems. 2nd ed. Wallingford: CBA International, 2001. 448 p.

GUERRA, J. G. M. et al. Desempenho de leguminosas tropicais perenes como plantas de cobertura do solo. Seropédica: Embrapa Agrobiologia, 2007. 22 p. (Boletim de Pesquisa e Desenvolvimento, 20).

INMET. Instituto Nacional de Meteorologia. Disponível em: $<$ http://www.inmet.gov.br>. Acesso em: 30 set. 2009.

LEITE, L. F. C. et al. Decomposição e liberação de nutrientes de resíduos vegetais depositados sobre Latossolo Amarelo no Cerrado Maranhense. Revista Ciência Agronômica, v. 41, n. 01, p. $29-35,2010$. 
MELO FILHO, J. F.; SOUZA, A. L. V. O manejo e a conservação do solo do semi-árido baiano: desafios para sustentabilidade. Revista Bahia Agrícola, v. 07, n. 03, p. 50-60, 2006.

NASCIMENTO, J. T.; SILVA, I. F. Avaliação quantitativa e qualitativa da fitomassa de leguminosas para uso como cobertura de solo. Ciência Rural, v. 34, n. 03, p. 947-949, 2004.

OLIVEIRA, C. A. P. de; SOUZA, C. M. de. Influência da cobertura morta na umidade, incidência de plantas daninhas e de broca-do-rizoma (Cosmopolites sordidus) em um pomar de bananeiras (Musa ssp.). Revista Brasileira de Fruticultura, v. 25, n. 02, p. 345-347, 2003.

OLIVEIRA, F. L.; GOSCH, M. S. Potencial de leguminosas herbáceas de hábito ereto para adubação verde no cerrado do Tocantis. Revista Ciência Agroambiental, v. 02, n. 01, p. 17-24, 2007.

PERIN, A. et al. Desempenho agronômico de milho consorciado com feijão-de-porco em duas épocas de cultivo no sistema orgânico de produção. Ciência e Agrotecnologia, v. 31, n. 03, p. 903-908, 2007.

PERIN, A. et al. Desempenho de bananeiras consorciadas com leguminosas herbáceas perenes. Ciência e Agrotecnologia, v. 33, n. 06, p. 1511-1517, 2009.
PERIN, A. et al. Efeito da cobertura viva com leguminosas herbáceas perenes na agregação de um argissolo. Revista Brasileira de Ciência do Solo, v. 26, n. 30, p. 713-720, 2002.

PERIN, A.; TEIXEIRA, M. G.; GUERRA, J. G. M. Desempenho de algumas leguminosas com potencial para utilização como cobertura permanente de solo. Agronomia, v. 34, n. 02 , p. $38-43,2000$.

SILVA, A. C.; HIRATA, E. K.; MONQUERO, P. A. Produção de palha e supressão de plantas daninhas por plantas de cobertura, no plantio direto do tomateiro. Pesquisa Agropecuária Brasileira, v. 44, n. 01, p. 22-28, 2009.

SOUZA FILHO, A. P. S.; ALVES, S. M.; FIGUEIREDO, F. J. C. Efeitos alelopáticos do calopogônio em função de sua idade e da densidade de sementes da planta receptora. Planta Daninha, v. 21, n. 02, p. 211-218, 2003.

STRECK, N. A.; SCHNEIDER, F. M.; BURIOL, G. A. Modificações físicas causadas pelo Mulching. Revista Brasileira de Agrometerologia, v. 02, n. 01, p. 131-142, 1994.

TORRES, J. L. R. et al. Influência de plantas de cobertura na temperatura e umidade do solo na rotação de culturas milhosoja em plantio direto. Revista Brasileira de Agrociência, v. 12, n. 01, p. 107-113, 2006. 